\title{
Synthesis and Characterization of Novel Aromatic Polyamides from 1,4-Bis(4-aminophenyl)-2,3-diphenylnaphthalene and Aromatic Dicarboxylic Acids
}

\author{
Atsushi Morikawa ${ }^{\dagger}$ and Tadashi Hatakeyama \\ Department of Materials Science, Faculty of Engineering, Ibaraki University, \\ 4-12-1 Nakanarusawa, Hitachi, Ibaraki, 316-8511, Japan
}

(Received July 28, 1998)

\begin{abstract}
A new highly phenylated diamine, 1,4-bis(4-aminophenyl)-2,3-diphenylnaphthalene, was synthesized in two steps starting from 2,5-bis(4-nitrophenyl)-3,4-diphenylcyclopentadienone. New aromatic polyamides containing tetraphenylnaphthalene unit were prepared by low temperature solution polycondensation of this diamine with various aromatic dicarboxylic acid chlorides. These polyamides had inherent viscosities of $0.45-0.82 \mathrm{dlg}^{-1}$. Polyamides with $m$-phenylene moiety and flexible connecting group were soluble in various organic solvents such as $N, N$-dimethylacetamide and $N$-methyl-2pyrrolidone, but those with rigid symmetric structures were soluble in only hot $N, N$-dimethylacetamide and $N$-methyl-2pyrrolidone. The glass transition temperature of the polyamides ranged from 268 to $366^{\circ} \mathrm{C}$, and the $10 \%$ weight loss temperatures were above $500^{\circ} \mathrm{C}$ in air.

KEY WORDS High Temperature Polymers / Soluble Aromatic Polyamides / 1,4-Bis(4-aminophenyl)2,3-diphenylnaphthalene / Thermal Behavior /
\end{abstract}

Aromatic polyamides are high thermal stability coupled with high crystallinity and hence high temperature application especially as fibers. ${ }^{1}$ However, most wholly aromatic polyamides are difficult to fabricate because of low solubility and high melting temperature. Several attempts have been made to improve the solubility by modifying the structure without losing their good thermal stability. Aromatic polyamides having phenyl-pendant structures such as tetraphenylthiophene, ${ }^{2-5}$ tetraphenylfuran, ${ }^{6}$ tetraphenylpyrrole, ${ }^{7}$ tetraphenylethylene,${ }^{8}$ triphenylamine,${ }^{9}$ triphenylphosphine, ${ }^{10}$ triphenylbenzene, ${ }^{11}$ hexaphenylbenzene, ${ }^{12}$ and tetraphenylquinquephenyl, ${ }^{13}$ have high thermal stability and high solubility. We conducted the synthesis of a new diamine monomer, 1,4-bis(4-aminophenyl)-2,3-diphenylnaphtalene and aromatic polyamides derived from it. This article deals with the synthesis and characterization of novel aromatic polyamides from this diamine and aromatic dicarboxylic acid chlorides. The properties of polyamides such as solubility and thermal behavior are also discussed.

\section{EXPERIMENTAL}

\section{Materials}

Isophthaloyl chloride (IVa), terephtaloyl chloride (IVb), 4,4'-biphenyldicarbonyl chloride (IVc), 4,4'-oxybibenzoyl chloride (IVd), and 4,4'sulfonyldibenzoyl chloride (IVe) were obtained commercially and purified by distillation under reduced pressure. $N, N$-Dimethylacetamide (DMAc) was purified by vacuum distillation over calcium hydride. 2,5-Bis(4-nitrophenyl)-3,4-diphenylcyclopentadienone (I) ${ }^{12}$ and 2-phenyliodoniobenzoate, ${ }^{14}$ a precursor for benzyne, were prepared as previously reported.

\footnotetext{
$\dagger$ To whom correspondence should be addressed.
}

\section{Monomer Synthesis}

1,4-Bis(4-nitrophenyl)-2,3-diphenylnaphthalene (II). In a flask, $7.11 \mathrm{~g}(15 \mathrm{mmol})$ of compound $\mathbf{I}$ and $5.50 \mathrm{~g}$ $(17 \mathrm{mmol})$ of 2-phenyliodoniobenzoate were dissolved in $50 \mathrm{ml}$ triethylene glycol dimethyl ether and the mixture was stirred at $210^{\circ} \mathrm{C}$ for about $10 \mathrm{~min}$. The solution turned colorless, and was cooled to about $100^{\circ} \mathrm{C}$ and the solvent was evaporated under reduced pressure of 15-20 Torr. The residue was washed with methanol and dried under reduced pressure. The crude product was purified by silica gel column chromatography eluted by dichloromethane and hexane $(4: 1) . \mathrm{mp} 316-317^{\circ} \mathrm{C}$. The yield was $5.40 \mathrm{~g}(69 \%)$. The IR spectrum $(\mathrm{KBr})$ exhibited absorption bands at 1520 and $1350 \mathrm{~cm}^{-1}\left(-\mathrm{NO}_{2}\right)$, and $700 \mathrm{~cm}^{-1}$ (naphthalene ring). ${ }^{1} \mathrm{H}$ NMR spectrum $[\delta$ in $\mathrm{CDCl}_{3}$ ] showed signals at $6.80-6.90(\mathrm{~m}, 10 \mathrm{H}), 7.40$ and $8.14(\mathrm{ABq}, 8 \mathrm{H}, J=9 \mathrm{~Hz}), 7.47(\mathrm{~m}, 2 \mathrm{H})$, and $7.52 \mathrm{ppm}$ $(\mathrm{m}, 2 \mathrm{H}) .{ }^{13} \mathrm{C}$ NMR spectrum $\left[\delta\right.$ in $\left.\mathrm{CDCl}_{3}\right]$ exhibited peaks at 146.6, 139.1, 139.0, 137.1, 132.1, 131.2, 130.9, $127.1,126.8,126.4,126.2$, and $122.9 \mathrm{ppm}$.

Anal. Calcd for $\mathrm{C}_{34} \mathrm{H}_{22} \mathrm{~N}_{2} \mathrm{O}_{4}$ : C, $78.15 \% ; \mathrm{H}, 4.24 \%$; $\mathrm{N}, 5.36 \%$. Found: C, $78.21 \%$; H, $4.28 \%$; N, $5.35 \%$.

1,4-Bis(4-aminophenyl)-2,3-diphenylnaphthalene (III). A mixture of $5.23 \mathrm{~g}(10 \mathrm{mmol})$ of compound II and $0.3 \mathrm{~g}$ of $10 \% \mathrm{Pd} / \mathrm{C}$ in $50 \mathrm{ml}$ of $N, N$-dimethylformamide was stirred at $70^{\circ} \mathrm{C}$ for $12 \mathrm{~h}$ under a hydrogen atmosphere. After $\mathrm{Pd} / \mathrm{C}$ was removed by filtration, the solvent was evaporated under reduced pressure and the crude product was purified by distillation under reduced pressure (Glass tube oven). bp $330^{\circ} \mathrm{C}$ ( 1 Torr). $\mathrm{mp} 279-$ $280^{\circ} \mathrm{C}$. The yield was $3.89 \mathrm{~g}(84 \%)$. The IR spectrum $(\mathrm{KBr})$ exhibited absorption bands at 3450 and 3360 $\mathrm{cm}^{-1}\left(-\mathrm{NH}_{2}\right)$, and $695 \mathrm{~cm}^{-1}$ (naphthalene ring). ${ }^{1} \mathrm{H}$ NMR spectrum $\left[\delta\right.$ in $\left.\mathrm{CDCl}_{3}\right]$ showed signals at 6.57 and $6.97(\mathrm{ABq}, 8 \mathrm{H}, J=8 \mathrm{~Hz}), 6.80-6.90(\mathrm{~m}, 10 \mathrm{H})$, $7.37(\mathrm{~m}, 2 \mathrm{H})$, and $7.73 \mathrm{ppm}(\mathrm{m}, 2 \mathrm{H}) .{ }^{13} \mathrm{C}$ NMR spectrum $\left[\delta\right.$ in $\left.\mathrm{CDCl}_{3}\right]$ exhibited peaks at 144.4, 141.0, $139.1,138.0,132.5,132.1,131.3,129.8,127.1,126.5$, $125.6,125.0$, and $114.4 \mathrm{ppm}$. 
Anal. Calcd for $\mathrm{C}_{34} \mathrm{H}_{26} \mathrm{~N}_{2}: \mathrm{C}, 88.28 \% ; \mathrm{H}, 5.66 \% ; \mathrm{N}$, $6.06 \%$. Found: C, $88.22 \% ; \mathrm{H}, 5.62 \%$; N, $6.12 \%$.

\section{Polymerization}

A typical polycondensation is given below.

Polyamide Va from III and IVa. In a three necked flask, a solution of $0.693 \mathrm{~g}(1.5 \mathrm{mmol})$ of diamine III and $5 \mathrm{ml}$ DMAc was chilled in a dry ice-acetone bath under nitrogen. To this, $0.304 \mathrm{~g}(1.5 \mathrm{mmol})$ of solid diacid chloride IVa was added all at once. The mixture was stirred at $4^{\circ} \mathrm{C}$ in ice-water bath. The polymerization proceeded as the solid was dissolved. After stirring at the temperature for $5 \mathrm{~h}$, the reaction mixture was poured into $400 \mathrm{ml}$ methanol, and dried at $100^{\circ} \mathrm{C}$ under vacuum. The yield was $0.86 \mathrm{~g}(97 \%)$. The inherent viscosity of the polymer in concentrated sulfuric acid was $0.53 \mathrm{dl} \mathrm{g}^{-1}$ at a concentration of $0.5 \mathrm{gdl}^{-1}$ at $30^{\circ} \mathrm{C}$. The IR spectrum (Film) exhibited absorption bands at $3380 \mathrm{~cm}^{-1}(\mathrm{~N}-\mathrm{H})$ and $1660 \mathrm{~cm}^{-1}(\mathrm{C}=\mathrm{O})$.

Anal. Calcd for $\left(\mathrm{C}_{42} \mathrm{H}_{28} \mathrm{~N}_{2} \mathrm{O}_{2}\right)_{n}$ : C, $85.11 \% ; \mathrm{H}, 4.76 \%$; N, $4.73 \%$. Found: C, $84.75 \% ; \mathrm{H}, 4.70 \%$; N $4.68 \%$.

\section{Measurements}

${ }^{1} \mathrm{H}$ and ${ }^{13} \mathrm{C}$ NMR spectra and IR spectra were recorded on a JNM- GSX-400 FT-NMR spectrometer and a Shimadzu Spectro Photometer IR 435, respectively. $\mathrm{X}$-Ray diffraction measurement was made with a Rigaku RAD-B System. Differential scanning calorimetry (DSC) and thermogravimetry (TG) analysis were a Rigaku Thermal Analysis Station TAS 100 and TG 8110, respectively, at a heating rate of $10^{\circ} \mathrm{Cmin}^{-1}$ in air and nitrogen.

\section{RESULTS AND DISCUSSION}

\section{Monomer Synthesis}

A new aromatic diamine having tetraphenylnaphthalene structure, 1,4-bis(4-aminophenyl)-2,3-diphenylnaphthalene (III), was synthesized in two steps starting from 2,5-bis(4-nitrophenyl)-3,4-diphenylcyclopentadienone (I) according to eq 1 .

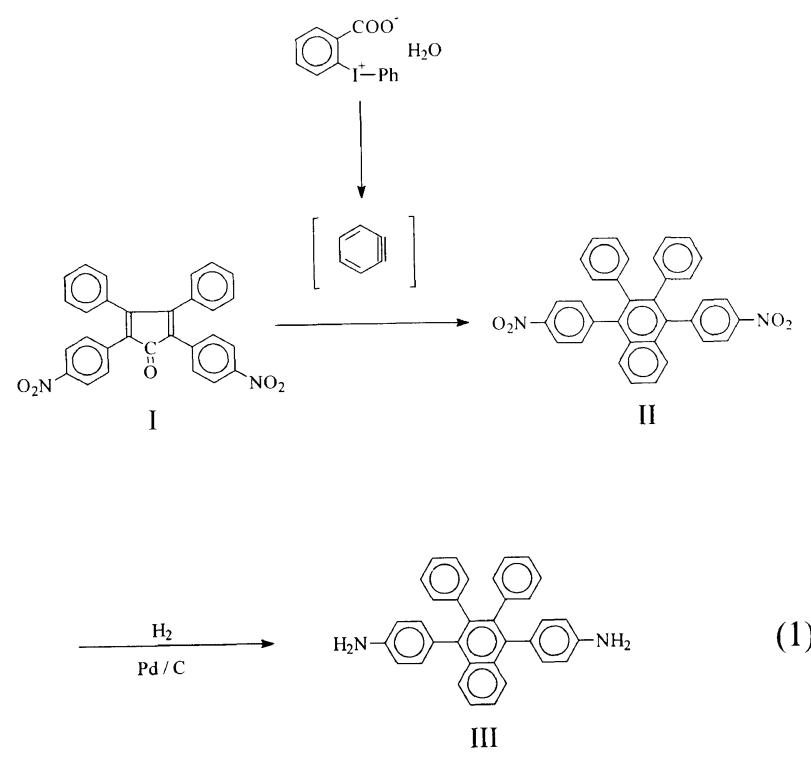

Compound (I) was reacted with the intermediate benzyne generated by heating 2-phenyliodoniobenzoate to yield 1,4-bis(4-nitrophenyl)-2,3-diphenylnaphthalene (II) in $69 \%$. Reaction conditions were the same as those of Beringer et al. for the preparation of 1,2,3,4-tetraphenylnaphthalene. ${ }^{14}$ Subsequent hydrogenation of the dinitro compound using $\mathrm{Pd} / \mathrm{C}$ as catalyst afforded 1,4bis(4-aminophenyl)-2,3-diphenylnaphthalene in $84 \%$ yield.

Chemical structures were comfirmed by IR and NMR spectra, and elemental analysis. In the synthesis of compound II, the disappearance of the characteristic carbonyl band at $1715 \mathrm{~cm}^{-1}$ was observed on the IR spectrum together with the appearance of resonances at $7.47 \mathrm{ppm}$ and $7.52 \mathrm{ppm}$ due to protons connected with naphthalene ring on the ${ }^{1} \mathrm{H}$ NMR spectrum. Compound III showed IR absorption at 3450 and $3360 \mathrm{~cm}^{-1}$ characteristic of amino group. The ${ }^{13} \mathrm{C}$ NMR spectrum of III exhibited 13 peaks due to symmetry, indicating the formation of the postulated diamine. Elemental analysis of all the compounds was also in good agreement with calculated results for the proposed structures.

\section{Polymer Synthesis}

Aromatic polyamides containing tetraphenylnaphthalene unit were prepared by the temperature solution polycondensation of 1,4-bis(4-aminophenyl)-2,3-diphenylnaphthalene (III) with various aromatic dicarboxylic acid chlorides (IVa-IVe) in DMAc (eq 2). Most polycondensations proceeded in a homogeneous solution, except for polymerization with IVb and IVc where precipitation of the polymers occurred during reaction because of low solubility of polymer Vb and Vc in DMAc.
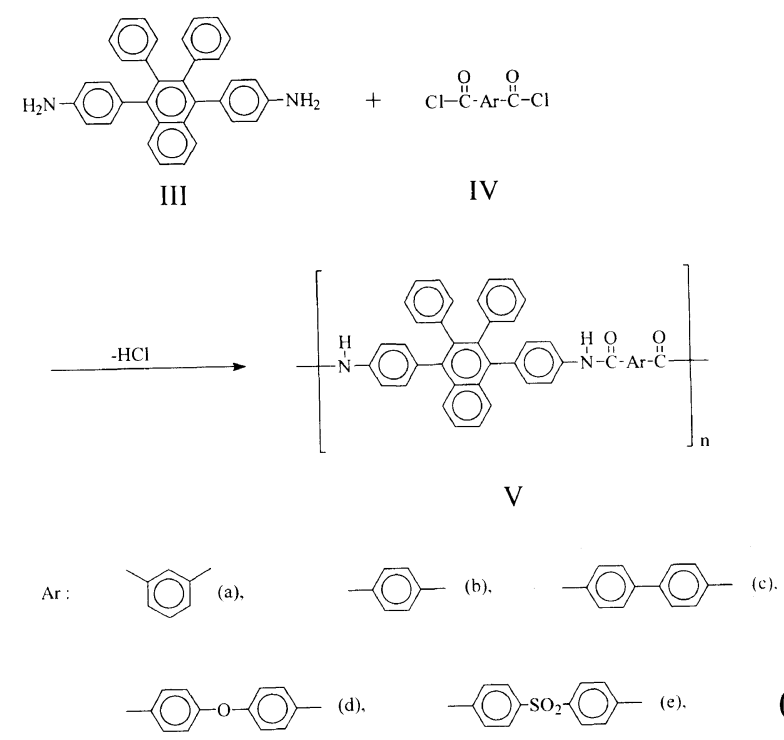

The results of synthesis of the aromatic polyamides are summarized in Table I. Inherent viscosities of the polymers were in the range of $0.45-0.82 \mathrm{dlg}^{-1}$, and most polyamides gave films by casting from the DMAc solutions. IR spectra of these polymers showed characteristic amide absorption bands at around 3360 $\mathrm{cm}^{-1}(\mathrm{~N}-\mathrm{H})$ and $1660 \mathrm{~cm}^{-1}(\mathrm{C}=\mathrm{O})$, which confirmed the formation of the proposed polyamides. 
Table I. Synthesis of aromatic polyamides ${ }^{a}$

\begin{tabular}{|c|c|c|c|c|}
\hline \multirow{3}{*}{$\begin{array}{l}\text { Diacid } \\
\text { chloride }\end{array}$} & \multicolumn{3}{|c|}{ Polymer } & \multirow{3}{*}{ Remarks ${ }^{\mathrm{c}}$} \\
\hline & \multirow{2}{*}{ Code } & Yield & $\eta_{\mathrm{inh}}^{\mathrm{b}}$ & \\
\hline & & $\%$ & $\mathrm{dl} \mathrm{g}^{-1}$ & \\
\hline IVa & $\mathbf{V a}$ & 97 & 0.53 & $\mathrm{~S}$ \\
\hline IVb & $\mathbf{V b}$ & 96 & 0.45 & $P$ \\
\hline IVc & Vc & 92 & 0.63 & $P$ \\
\hline IVd & Vd & 95 & 0.74 & $\mathrm{~S}$ \\
\hline IVe & Ve & 94 & 0.82 & $S$ \\
\hline
\end{tabular}

${ }^{\text {a }}$ Polymerization was carried out with $1.5 \mathrm{mmol}$ of each monomer in $5.0 \mathrm{ml}$ DMAc at $4^{\circ} \mathrm{C}$ for $5 \mathrm{~h}$ under nitrogen. ${ }^{b}$ Measured at $0.5 \mathrm{~g} \mathrm{dl}^{-1}$ in concentrated sulfuric acid at $30^{\circ} \mathrm{C}$. ${ }^{\circ}$ Appearance of the polymerization system: $\mathrm{S}$, homogeneous solution; $\mathrm{P}$, polymer precipitation.

Table II. Solubility of aromatic polyamides

\begin{tabular}{lccccc}
\hline \multirow{2}{*}{ Solvent } & \multicolumn{5}{c}{ Polymer } \\
\cline { 2 - 6 } & Va & Vb & Vc & Vd & Ve \\
\hline$N$-Methyl-2-pyrrolidone & ++ & + & + & ++ & ++ \\
$N, N$-Dimethylacetamide & ++ & + & + & ++ & ++ \\
$N, N$-Dimethylformamide & ++ & - & - & ++ & ++ \\
$m$-Cresol & ++ & - & - & ++ & + \\
Pyridine & ++ & - & - & + & + \\
\hline
\end{tabular}

${ }^{\text {a }}$ Solubility: ++ , soluble at room temperature; + , soluble on heating; - , insoluble.

\section{Polymer Characterization}

Table II lists qualitative solubility of the tetraphenylnaphthalene containing aromatic polyamides. Polymer Va with $m$-phenylene moiety as well as polymer Vd and Ve having flexible connecting groups was more soluble than the other polymers ( $\mathbf{V b}$ and $\mathbf{V c})$ with rigid symmetric structures, and dissolved in $N$-methylpyrrolidone (NMP), DMAc, and $N, N$-dimethylformamide even at room temperature. Polyamides, $\mathbf{V b}$ and $\mathbf{V c}$, with rigid symmetric structure were soluble only in hot NMP and DMAc. All polymers were entirely insoluble in methanol, acetone, chloroform and tetrahydrofuran. The solubility of the tetraphenylnaphthalene-based polyamides was lower than that of aromatic polyamides having similar phenyl-pendant structures such as tetraphenylthiophene, ${ }^{2-5}$ tetraphenylfuran, ${ }^{6}$ tetraphenylpyrrole, ${ }^{7}$ tetraphenylethylene, ${ }^{8}$ triphenylamine, ${ }^{9}$ and triphenylphosphine, ${ }^{10}$ previously reported soluble in NMP at room temperature. The rigid terphenyl structure without hetero-atom in the tetraphenylnaphthalene may cause the low solubility.

$\mathrm{X}$-Ray diffraction studies indicated that these polyamides, even $\mathbf{V b}$ and Vc, which had rigid symmetric structure, were amorphous. The amorphous nature of these polymers was not reflected by solubility.

The thermal behavior of the polyamides was evaluated by TG and DSC. Figure 1 shows typical DSC and TG curves of polyamide $\mathbf{V a}$. The glass transition temperatures $\left(T_{\mathrm{g}}\right)$ and $10 \%$ weight loss temperature $\left(T_{10}\right)$ are summarized in Table III. The present polyamides had relatively high $T_{\mathrm{g}}$ in the range of $268-366^{\circ} \mathrm{C}$. Polyamides $\mathbf{V b}$ and $\mathbf{V c}$ having rigid symmetric structures had higher $T_{\mathrm{g}}$ than the polymers (Va, Vd, and Ve) with unsymmetric

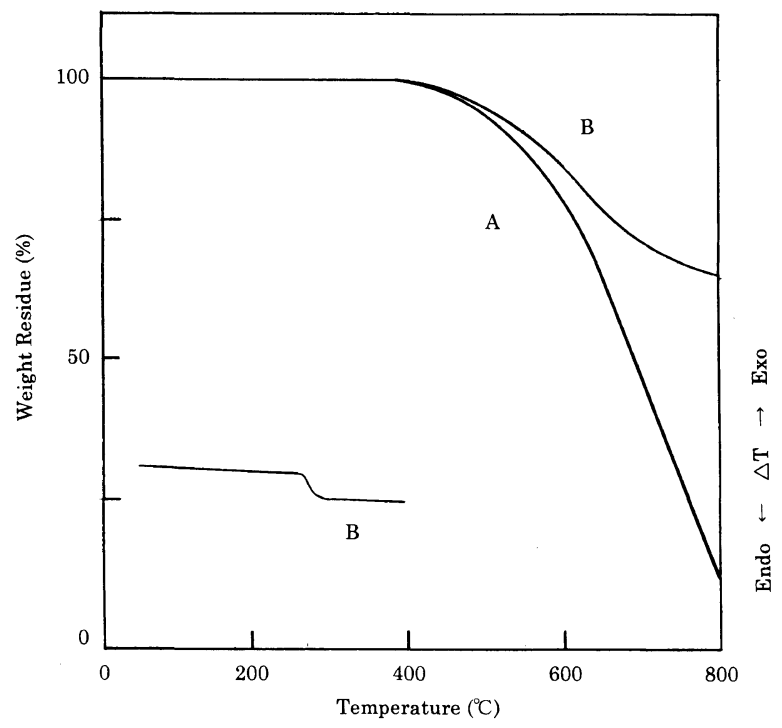

Figure 1. DSC and TG curves for polyamide $\mathbf{V a}$ at heating rate of $10^{\circ} \mathrm{Cmin}^{-1}$ in (A) air and (B) nitrogen.

Table III. Thermal behavior of aromatic polyamides

\begin{tabular}{|c|c|c|c|c|}
\hline \multirow{4}{*}{ Polymer } & \multirow{4}{*}{$\frac{T_{\mathrm{g}}^{\mathrm{a}}}{{ }^{\circ} \mathrm{C}}$} & \multicolumn{2}{|c|}{$T_{10}{ }^{\mathrm{b}}$} & \multirow{4}{*}{$\frac{\text { Char yield }}{\mathrm{c}}$} \\
\hline & & \multirow{3}{*}{$\frac{\text { In air }}{{ }^{\circ} \mathrm{C}}$} & \multirow{3}{*}{$\frac{\text { In nitrogen }}{{ }^{\circ} \mathrm{C}}$} & \\
\hline & & & & \\
\hline & & & & \\
\hline $\mathbf{V a}$ & 268 & 509 & 550 & 64 \\
\hline $\mathbf{V b}$ & 366 & 504 & 545 & 65 \\
\hline $\mathrm{Vc}$ & 353 & 503 & 538 & 60 \\
\hline Vd & 300 & 526 & 552 & 62 \\
\hline Ve & 335 & 490 & 530 & 55 \\
\hline
\end{tabular}

${ }^{a}$ Determined by DSC in nitrogen at a heating rate of $10^{\circ} \mathrm{Cmin}^{-1}$. ${ }^{b}$ Temperature at which there was $10 \%$ weight loss by TG at heating rate of $10^{\circ} \mathrm{C} \mathrm{min}^{-1}$. ${ }^{\mathrm{c}} \mathrm{Char}$ yield in nitrogen at $800^{\circ} \mathrm{C}$ by $\mathrm{TG}$.

ones and flexible connecting group.

None of the present polyamides lost weight below $400^{\circ} \mathrm{C}$ in air or nitrogen, and $T_{10}$ in air and nitrogen were ranged from $514-536^{\circ} \mathrm{C}$ and $520-544^{\circ} \mathrm{C}$, respectively, indicating high thermal stability. More than $60 \%$ weight was retained even at $800^{\circ} \mathrm{C}$ in nitrogen for the polyamides. Based on $T_{10}$, the tetraphenylnaphtalenebased polyamides had as high thermal stability as tetraphenylthiophene-based polyamide,${ }^{15}$ the most thermally stable polymer in the aromatic polyamide with similar phenyl pendant structure.

\section{CONCLUSION}

We synthesized a new highly phenylated diamine, 1,4-bis(4-aminophenyl)-2,3-diphenylnaphthalene, which was subsequently used for the polycondensation with aromatic dicarboxylic acid chlorides to obtain aromatic polyamides. The polyamides were soluble in polar organic solvents, such a $N, N$-dimethylacetamide and $N$-methyl-2-pyrrolidone, and had high glass transition temperatures and high thermal stability. 


\section{REFERENCES}

1. P. E. Cassidy, "Thermally Stable Polymers," Dekker, New York, N. Y., 1980.

2. M. Kakimoto, Y. S. Negi, and Y. Imai, J. Polym. Sci., Polym. Chem. Ed., 23, 1787 (1985).

3. Y. Imai, N. N. Maldar, and M. Kakimoto, J. Polym. Sci., Polym. Chem. Ed., 23, 1797 (1985).

4. Y. Imai and M. Kakimoto, Polym. Plast. Technol. Eng., 28, 371 (1989).

5. H.-J. Jeong, A. Kobayashi, M. Kakimoto, and Y. Imai, Polym. J., 26, 99 (1994).

6. H.-J. Jeong, Y. Oishi, M. Kakimoto, and Y. Imai, J. Polym. Sci., A, Polym. Chem. Ed., 28, 3293 (1990).
7. H.-J. Jeong, M. Kakimoto, and Y. Imai, J. Polym. Sci., A, Polym. Chem. Ed., 29, 767 (1991).

8. M.-L. Xie, Y. Oishi, M. Kakimoto, and Y. Imai, J. Polym. Sci., A, Polym. Chem. Ed., 29, 55 (1991).

9. Y. Oishi, H. Takado, M. Yoneyama, M. Kakimoto, and Y. Imai, J. Polym. Sci., A, Polym. Chem. Ed., 28, 1763 (1990).

10. M. Yamashita, M. Kakimoto, and Y. Imai, J. Polym. Sci., A, Polym. Chem. Ed., 31, 1513 (1993).

11. I. K. Spiliopoulos and J. A. Mikroyannidis, Macromolecules, 31, 1236 (1998).

12. Y. Sakaguchi and F. W. Harris, Polym. J., 24, 1147 (1992).

13. I. K. Spiliopoulos and J. A. Mikroyannidis, Macromolecules, 31, 515 (1998).

14. F. M. Beringer and S. J. Huang, J. Org. Chem., 29, 445 (1964).

15. Y. Imai, High Perform. Polym., 7, 337 (1995). 